\title{
Comparison of Thermal Performance Characteristics of Ammonia and Propylene Loop \\ Heat Pipes
}

\author{
Tarik Kaya \\ International Space University \\ Strasbourg, France
}

\author{
Charles Baker \\ Orbital \\ Greenbelt, MD, USA
}

\author{
Jentung Ku \\ NASA Goddard Space Flight Center \\ Greenbelt, MD, USA
}

\begin{abstract}
In this paper, experimental work performed on a breadboard Loop Heat Pipe (LHP) is presented The test article was built by DCI for the Geoscience Laser Altimeter System (GLAS) instrument on the ICESat spacecraft. The thermal system requirements of GLAS have shown that ammonia cannot be used as the working fluid in this LHP because GLAS radiators could cool to well below the freezing point of ammonia. As a result, propylene was proposed as an alternative LHP working fluid since it has a lower freezing point than ammonia. Both working fluids were tested in the same LHP following a similar test plan in ambient conditions. The thermal performance characteristics of ammonia and propylene LHP's were then compared. In general, the propylene LHP required slightly less startup superheat and less control heater power than the ammonia LHP. The thermal conductance values for the propylene LHP were also lower than the ammonia LHP. Later, the propylene LHP was tested in a thermal vacuum chamber. These tests demonstrated that propylene could meet the GLAS thermal design requirements. Design guidelines were proposed for the next flight-like Development Model (DM) LHP for thermal control of the GLAS instrument.
\end{abstract}

\section{INTRODUCTION}

Loop Heat Pipes (LHP's) are rapidly gaining acceptance in the aerospace industry due to their performance advantages and reliability. LHP's inherent versatility has spawned many new designs in response to increasingly stringent spacecraft thermal requirements. Terrestrial applications of the LHP's are also highly promising. A detailed analysis of the working principles of the LHP's can be found in Refs. 1 and 2.

In this study, the thermal performance characteristics of a breadborad LHP were investigated. This LHP was designed for the thermal control of the Geoscience Laser Altimeter System (GLAS) instrument on the ICESat spacecraft, scheduled for launch in 2001. The GLAS instrument's mission is to measure ice-sheet topography and associated temporal changes, as well as cloud and atmospheric properties. The GLAS instrument utilizes three lasers, each of which dissipates approximately $100 \mathrm{~W}$ when operating, and only one laser is needed at a time. The spacecraft is in near circular and near polar orbit at an altitude of approximately $600 \mathrm{~km}$. This orbit passes through all beta angles varying from $90^{\circ}$ to $-90^{\circ}$. The thermal environment therefore is highly variable. The lasers on the GLAS instrument have to meet very tight structural distortion requirements, which dictates tight temperature stability conditions. Therefore, design of thermal control system is highly challenging and a thermal operating range of $283 \pm 0.5 \mathrm{~K}$ needs to be satisfied. In addition, the GLAS thermal system requirements include a worst case LHP startup from a sun acquisition spacecraft mode. It was shown that in this mode the LHP radiators could $\mathrm{cool}$ to $173 \mathrm{~K}$ which is well below the freezing point of ammonia. Due to limited survival heater power available on the ICESat spacecraft, the ammonia LHP could not meet the design requirements. Freeze tolerant condenser tubing was seen as more risky and design-inflexible than using another working fluid with a lower freezing point such as propylene.

Propylene is much more commonly used as a working fluid in the Russian LHP designs. At NASA Goddard Space Flight Center (GSFC), there was however no prior data on the thermal performance of the propylene LHP's. To prove the concept, the breadboard ammonia LHP was first recharged with propylene. The propylene LHP was then tested by following a similar test plan developed earlier for the ammonia LHP tests. Later, the breadboard propylene LHP was tested in a thermal vacuum chamber to find out the required superheat and overshoot temperatures during startup. Along with the startup tests, the required control heater power to maintain the compensation chamber temperature at a desired setpoint was also measured. The purpose of the 
thermal vacuum tests was to mitigate risk prior to receiving the flight-like Development Model (DM) LHP. If anomalies are identified in these tests on the breadboard LHP, design improvements could be made on the DM LHP design.

\section{EXPERIMENTAL SETUP}

The test article used in this study is schematically presented in Fig. 1. The breadboard LHP had a sintered nickel wick with an effective pore radius of approximately 1.2 microns. The detailed design and performance characteristics of this LHP can be found in Ref. 3.

For tests in ambient conditions, 61 copper/constantan (type T) thermocouples were used to monitor the temperatures of the LHP and environment. The uncertainty of the thermocouple readings was estimated to be $\pm 0.5 \mathrm{~K}$. The LHP condenser was a single pass and direct condensation heat exchanger type. The condenser lines were cooled by a chiller with a $1.5 \mathrm{~kW}$ cooling capacity. The chiller fluctuations were within $\pm 1 \mathrm{~K}$ of the chosen set point. All the LHP components were insulated with $15 \mathrm{~mm}$-thick Armaflex material.

For thermal vacuum tests, the LHP was instrumented by 72 type-T thermocouples. Tests were carried out in a cryo-pumped DynaVac thermal vacuum chamber with a payload area of $914 \mathrm{~mm}$ in diameter and $1170 \mathrm{~mm}$ in height. Indium in several layers was used as thermal filler between the evaporator saddle and the heaters. Radiative couplings between the LHP and its surroundings were minimized, wherever required, by using MLI blanketing.

The heat was applied by using three cartridge heaters with a total maximum electrical power of $1500 \mathrm{~W}$. The cartridge heaters were mounted on one side of the copper evaporator saddle. For the control power requirement test, two different thermostatically controlled heaters ( $10 \mathrm{~W}$ and 20 $W$ ) were used on the compensation chamber. The temperature control was achieved either by a proportional controller or an on/off type controller. The uncertainty in measuring the power input was estimated to be less than $2 \%$. Sampling rate of the data acquisition system was $10 \mathrm{kHz}$ with a resolution of 16-bit and an analog-to-digital-converter system accuracy of $0.6 \%$.

\section{DISCUSSION OF RESULTS}

AMBIENT TESTS

For the ambient tests, the condenser plate of the LHP was oriented in a vertical plane as shown in Fig. 1. The evaporator and the compensation chamber were leveled within $\pm 2.5 \mathrm{~mm}$ from one end to other in the horizontal plane. Tests were performed at two different sink conditions: $273 \mathrm{~K}$ and $293 \mathrm{~K}$. During the tests the average ambient temperature was $294 \mathrm{~K}$. Previous tests performed in various orientations showed that there was vapor connection between the evaporator and the compensation chamber in this orientation. ${ }^{3}$. For some of the tests, the compensation chamber was preheated prigr to applying power to the evaporator to ensure that the vapor grooves were flooded. This would create a less favorable condition for startup. Care should be taken in interpreting the results since preheating the compensation chamber may also lead to a liquid filled evaporator core, decreasing the heat leak and favoring the startup. However, the test results indicated that the core always had two-phase flow even after preheating the compensation chamber.

\section{Startup Tests}

For both the ammonia and propylene LHP's, the wall superheat values at startup were around 1.5 $K$. The propylene LHP required slightly less superheat than the ammonia LHP. However, the differences were within the estimated uncertainty of thermocouple readings of $\pm 0.5 \mathrm{~K}$. As a result, temperature overshoot values were measured to compare the two LHP startup performance. The temperature overshoot is defined as the difference between the average evaporator temperature at the startup and the average compensation chamber temperature before applying the power. Temperature overshoot values are important since the payload will experience these temperatures prior to startup. Temperature overshoot is related to superheat 
since startups having large overshoots tend to require large superheats for the same initial temperature before a startup. The test results indicated that the overshoot depends mainly on the initial conditions of the evaporator core and the vapor grooves. There are several other factors influencing overshoot, including how the LHP was previously shut down and the waiting time between a shut down and startup.

The measured temperature overshoot and wall superheat values are summarized in Table 1.

Table 1. Measured temperature overshoot and wall superheat values.

\begin{tabular}{|c|c|c|c|c|c|}
\hline Working fluid & $\begin{array}{c}\text { Startup } \\
\text { power }(\mathrm{W})\end{array}$ & $\begin{array}{c}\text { Sink } \\
\text { temp. }(\mathrm{K})\end{array}$ & $\begin{array}{c}\text { Compensation chamber } \\
\text { initial temperature (K) }\end{array}$ & $\begin{array}{c}\text { Temperature } \\
\text { overshoot (K) }\end{array}$ & $\begin{array}{c}\text { Wall } \\
\text { superheat (K) }\end{array}$ \\
\hline Ammonia & 50 & 273 & 293 & 27 & 1.7 \\
\hline \multirow{3}{*}{ Propylene } & 50 & 273 & 293 & 2.8 & 1.0 \\
\cline { 2 - 6 } & 30 & 273 & 285 & 13 & 1.2 \\
\cline { 2 - 6 } & 30 & 253 & 277 & 19 & 1.6 \\
\hline
\end{tabular}

The condenser sink temperature was first set to $273 \mathrm{~K}$. The compensation chamber temperature was controlled at $293 \mathrm{~K}$ to reduce the effects of heat exchange with ambient. $50 \mathrm{~W}$ was applied to the evaporator for startup. The ammonia LHP was started with a $27 \mathrm{~K}$ overshoot. At the same startup conditions, the propylene LHP started with an overshoot of $2.8 \mathrm{~K}$. This large difference in the overshoot could be attributed to the lower values of the related thermophysical properties of the propylene with respect to the ammonia (mainly surface tension, latent heat, and thermal conductivity).

Another set of startup tests was conducted on the propylene LHP to measure the overshoot temperatures in different power and sink conditions. The compensation chamber was heated prior to applying power to the evaporator in order to flood the vapor grooves. The condenser sink temperature was set to $273 \mathrm{~K}$ and $30 \mathrm{~W}$ instead of $50 \mathrm{~W}$ was applied to the evaporator for startup. An overshoot of $13 \mathrm{~K}$ was recorded. When the sink temperature was lowered to $253 \mathrm{~K}$, the overshoot was $19 \mathrm{~K}$. In all three of the propylene cases, the LHP started about the same temperature of $296 \mathrm{~K}$ and the overshoot values were obviously dictated by the initial temperature of the compensation chamber.

The propylene LHP was then tested in a reflux mode. In this orientation, the condenser was horizontal and above the evaporator and compensation chamber. The compensation chamber was located above the evaporator. The compensation chamber was again preheated to make sure that the vapor grooves and the evaporator core were flooded. As the evaporator core was completely flooded no vapor-liquid interface existed between the evaporator and compensation chamber, the heat leak was therefore substantially reduced. The condenser sink temperature was $273 \mathrm{~K}$ and startup power $30 \mathrm{~W}$. The compensation chamber initial temperature was $274 \mathrm{~K}$. The LHP started at $282 \mathrm{~K}$. The overshoot for the propylene LHP in this orientation was reduced to $8 \mathrm{~K}$ and a wall superheat of $5.8 \mathrm{~K}$ was recorded.

\section{Operating Temperature versus Power}

Results of the power cycle tests for the ammonia and propylene LHP's are shown in Fig. 2. Tests were performed with a sink temperature of $273 \mathrm{~K}$. For the same power level, the LHP steadystate operating temperatures were higher for the propylene LHP. These results can again be attributed to the lower values of the thermophysical properties of the propylene with respect to the ammonia.

\section{Heat Transport Limit}

The propylene LHP deprimed at around $500 \mathrm{~W}$ for both the horizontal and vertical condenser orientations. After deprime, the applied power was reduced to $400 \mathrm{~W}$ and then to $300 \mathrm{~W}$. It seemed that the LHP did not recover. When the power was further reduced to $200 \mathrm{~W}$, the fluid circulation in the LHP restarted. The ammonia LHP was tested to $800 \mathrm{~W}$ without any sign of 
deprime. No higher powers were attempted because of the chiller limitation. This result was expected since the ammonia has better ability to transport heat, which can be represented by the liquid transport factor $(\mathrm{M})$ :

$$
M=\frac{\rho, \sigma \lambda}{\mu_{i}}
$$

where $\rho_{l}$ is liquid density, $\sigma$ surface tension, $\lambda$ latent heat of vaporization, and $\mu_{l}$ liquid viscosity. At $293 \mathrm{~K}$, the liquid transport factor $(M)$ for ammonia is 6.7 times higher than that of
propylene.

\section{Control Heater Power}

Control heater power refers to the power provided to the compensation chamber control heaters in order to maintain the LHP operating temperature at a desired value. For the control power test, a $20-W$ control heater was used on the compensation chamber and the compensation chamber was maintained at $293 \mathrm{~K}$. The condenser sink temperature was set to $273 \mathrm{~K}$ for all the tests. Figure 3 shows the control power requirement for the propylene LHP at various powers for both the horizontal and vertical condenser. At higher powers, as the operating temperature of the LHP was approaching the control setpoint temperature, the required control heater power was leveling off. The ammonia LHP results were plotted in Fig. 4. The propylene LHP required lower control heater power than the ammonia LHP. This difference in the control power was discussed in more detail under the thermal vacuum test section of the paper.

\section{Evaporator Thermal Conductance}

The evaporator thermal conductance was calculated using

$$
C=Q_{A P P .} /\left(\bar{T}_{E r}-\bar{T}_{C C}\right)
$$

where $Q_{A P P}$ is the applied power, and $\bar{T}_{E V}$. and $\bar{T}_{C C}$ are the average evaporator and compensation chamber wall temperatures, respectively. The results were obtained with a condenser sink temperature of $273 \mathrm{~K}$ and shown in Fig. 5 . At low powers, the temperature difference between evaporator and compensation chamber wall temperatures was small and the conductance calculations were not accurate. Therefore, only thermal conductance values at high powers were presented in Fig. 5. For the ammonia LHP, the thermal conductance values were almost constant at the power range presented. This region corresponds to the constant overall resistance of the LHP. For the propylene LHP, the thermal conductance values started decreasing when the applied power was approaching the deprime value of $500 \mathrm{~W}$.

The evaporator thermal conductance of the propylene LHP was lower than the ammonia LHP. This result is again consistent with the earlier statement regarding the lower values of the thermophysical properties, mainly thermal conductivity, of the propylene.

\section{Steady State Operation at Low Power}

Both the ammonia and propylene LHP's operated continuously for more than 12 hours with a heat load of $25 \mathrm{~W}$. In both cases, the LHP operated successfully without any sign of performance degradation. The low power operational limit was not investigated.

\section{THERMAL VACUUM TESTS}

To simulate the space flight condition during the sun acquisition mode, the condenser of the LHP was cooled to $173 \mathrm{~K}$ in the thermal vacuum chamber. No mechanical risk was expected as the LHP evaporators of similar design have previously been cooled to $213 \mathrm{~K}$. However, the breadboard LHP was charged for a minimum non-operating temperature of $253 \mathrm{~K}$. The LHP thermal performance could then degrade because of the excessive cooling below the minimum 
design temperature. In order to increase the likelihood of being able to operate with an undercharged LHP, the condenser plate was oriented as horizontal as possible above the evaporator to ensure the liquid filling of the evaporator core prior to the start-up. Because of the limited diameter of the thermal vacuum chamber, the condenser panel was placed at about $60^{\circ}$ from the horizontal plane. Only propylene LHP was tested in the thermal vacuum chamber

\section{Startup Tests and Control Heater Power}

During the cooling of the thermal vacuum chamber, the LHP started by itself before the power was applied to the evaporator. After the startup, all the LHP temperatures continued to decrease. The LHP was shut down as soon as the evaporator temperature was dropped below the compensation chamber setpoint temperature of $248 \mathrm{~K}$. After the condenser plate reached $173 \mathrm{~K}$, $15 \mathrm{~W}$ was applied to the evaporator for the first startup test. The LHP was started with an overshoot temperature of $12 \mathrm{~K}$ and a superheat of $6 \mathrm{~K}$ as shown in Fig. 6 .

A remarkable observation during the startup test was the immediate shutdown of the LHP just after the startup, which is presented in Fig. 6 and explained as follows: The active control of the compensation chamber was achieved by a thermostatically controlled proportional heater of $20-\mathrm{W}$ maximum power. Immediately following the startup, a large amount of control heater power was required to maintain the compensation chamber at the setpoint temperature. However, if the compensation chamber was heated with a faster rate than the evaporator, the vapor grooves would be flooded by the liquid that was pushed out of the compensation chamber, shutting down the fluid circulation. After the shut down, the LHP started again since the power was continued to be applied to the evaporator. This process was repeated following the same cycle as long as the evaporator was under a heat load. Two of such cycles were presented in Fig. 6. In order to avoid the evaporator shut down, either the compensation chamber control power has to decrease or the evaporator power has to increase. In this test, the control heater power was reduced to $10 \mathrm{~W}$; however, this was not enough to maintain the compensation chamber setpoint temperature due to the very cold returning liquid from the condenser. A successful startup was finally obtained by an on/off type controller with a 10-W power heater. Table 2 summarizes the test results and calculations of the control heater power requirements for different settings.

Table 2. Compensation chamber control heater power requirements.

\begin{tabular}{|c|c|c|c|c|}
\hline $\begin{array}{l}\text { Applied power } \\
\text { (W) }\end{array}$ & $\begin{array}{l}\text { Setpoint temp. } \\
\text { (K) }\end{array}$ & $\begin{array}{l}\text { Measured control } \\
\text { heater power }(\mathrm{W})\end{array}$ & $\begin{array}{l}\text { Subcooling } \\
\text { calculated by Eq. (3) } \\
\text { (W) }\end{array}$ & $\begin{array}{l}\text { Heat leak } \\
\text { (W) }\end{array}$ \\
\hline 120 & 274.7 & 5.3 & 15.6 & 10.3 \\
\hline 150 & 273.2 & 3.3 & 12.4 & 11.1 \\
\hline 200 & 295.1 & 4.6 & 28.4 & 23.8 \\
\hline
\end{tabular}

For the control heater power measurements, the heater voltage and current were recorded during the tests. As the applied power increases, the control power decreases for a given setpoint temperature. Similarly, when the compensation chamber setpoint temperature increases, the required control power also increases. It should also be noted that care must be taken when increasing the compensation chamber setpoint in order not to shut down the LHP.

The required subcooling was calculated from the test data by using the following equation:

$Q=m C_{p}\left(T_{\text {vetponnt }}-T_{\text {liquid return }}\right)$

where $m$ is the mass flow rate, $C_{p}$ the liquid specific heat, $T_{\text {setpum }}$ the compensation chamber setpoint temperature, and $T_{\text {ligut return }}$ the temperature of the returning liquid. 
The heat leak was then calculated by subtracting the calculated subcooling from the measured control heater power. The resulting heat leak values were larger than those for no active control case. These results suggest that the external heating of the compensation chamber changes internal coupling in the evaporator core, leading to a higher heat leak. Test results obtained with the DM LHP unit may provide more insight into this phenomenon.

\section{Operating Temperature versus Power}

The test results are given in Fig. 7 for two different condenser sink temperatures of $173 \mathrm{~K}$ and $228 \mathrm{~K}$. The operating power varies almost linearly with the applied power. This type of curve is similar to the typical LHP curve during ambient testing when the sink temperature is higher than the surrounding temperature. In other words, the LHP performance curve in vacuum does not curve up at low powers as it happens in ambient conditions due to the parasitic convective heating.

\section{Evaporator Thermal Conductance}

Figure 8 shows the evaporator conductance values for the propylene LHP with a sink temperature of $173 \mathrm{~K}$. The evaporator conductance values were close to those previously obtained in ambient conditions over the same power range.

\section{CONCLUSIONS}

The thermal performance characteristics of the LHP using propylene as the working fluid were investigated. Based on the test of the breadboard unit, the propylene LHP should be able to the thermal system design requirements of the GLAS instrument on the ICESat spacecraft.

During startup tests, temperature overshoots as high as $13 \mathrm{~K}$ were observed. When comparing the ammonia and propylene LHP's, the propylene LHP had a lower heat transport limit and evaporator thermal conductance, and required lower control heater power and slightly less superheat at the boiling incipience.

Control of the compensation chamber setpoint is not a trivial task. If the compensation chamber is heated at a faster rate than the evaporator it is not possible to maintain the fluid circulation inside the LHP. The control heater power needs to be low enough to avoid an undesirable shut down and high enough to be able to heat the cold returning fluid to the desired setpoint temperature. The results indicated that the external heating of the compensation chamber changes internal coupling in the evaporator core, leading to a higher heat leak.

\section{ACKNOWLEDGMENTS}

This work was performed at NASA Goddard Space Flight Center (GSFC) through the funding of the GLAS project. A part of funding for thjs work was provided by National Research Council (NRC)-NASAVGSFC Resident Research Associateship Grant.

\section{REFERENCES}

1. Maidanik, Y. F., Fershtater, Y. F. and Solodovnik, N. N., "Design and Investigation of Regulation of Loop Heat Pipes for Terrestrial and Space Applications," Society of Automotive Engineers, Paper 941407, June 1994.

2. Ku, J., "Operational Characteristics of Loop Heat Pipes," Society of Automotive Engineers, Paper 1999-01-2007, July 1999.

3. Kaya, T. and $\mathrm{Ku}$, J., "Ground Testing of Loop Heat Pipes for Spacecraft Thermal Control," AIAA Paper 99-3447, July 1999.

4. Baker, C. L., Bienert, W. B., and Ducao, A. S., "Loop Heat Pipe Flight Experiment," Society of Automotive Engineers, Paper 98ES-80, July 1998. 


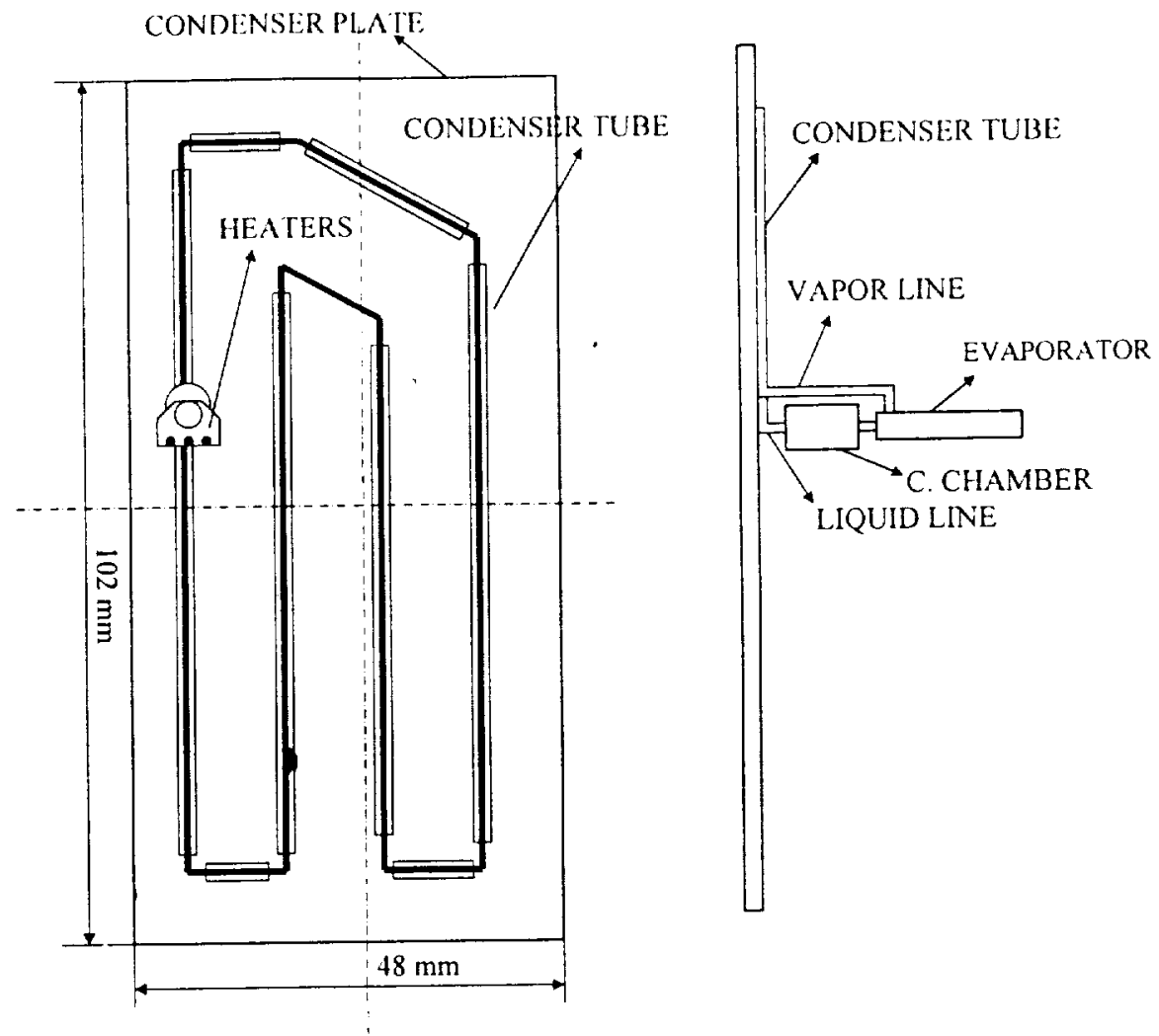

Figure 1. Schematic of the breadboard GLAS LHP.

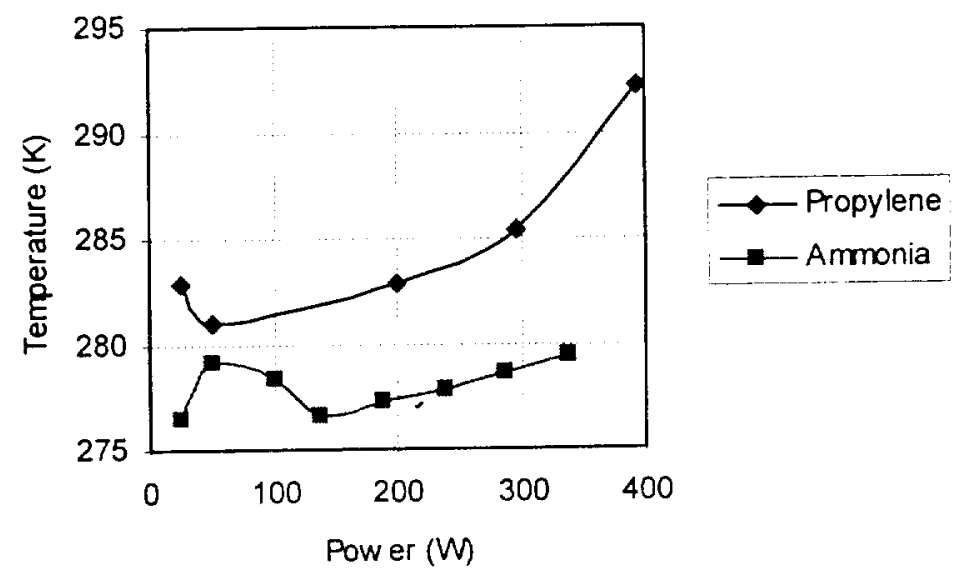

Figure 2. Operating temperature as a function of the applied power for ammonia and propylene LHP's. Tsink $=273 \mathrm{~K}$. 


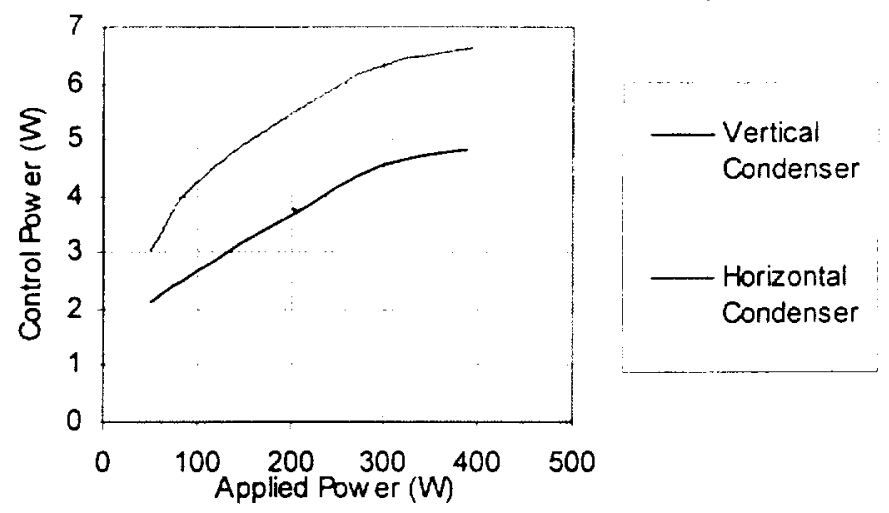

Figure 3. Control power requirement for propylene LHP at various power levels for horizontal and vertical condenser orientations."

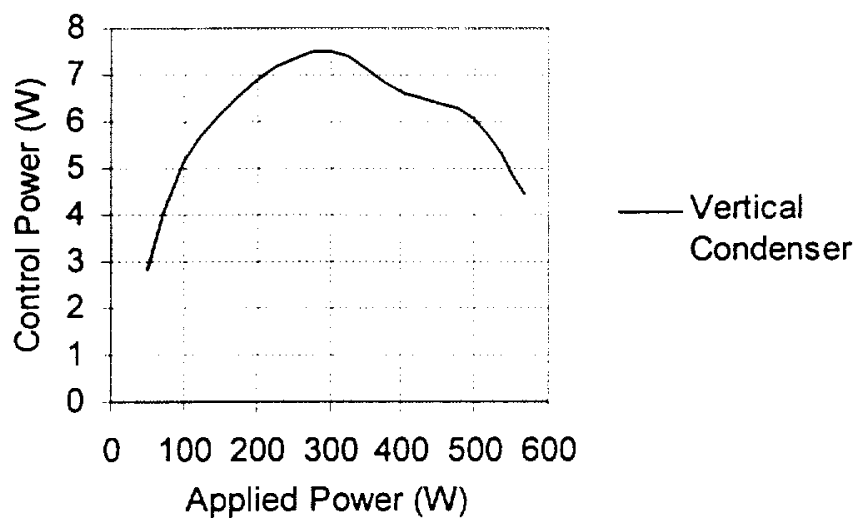

Figure 4. Control power requirement for ammonia LHP at various power levels for vertical condenser orientation.

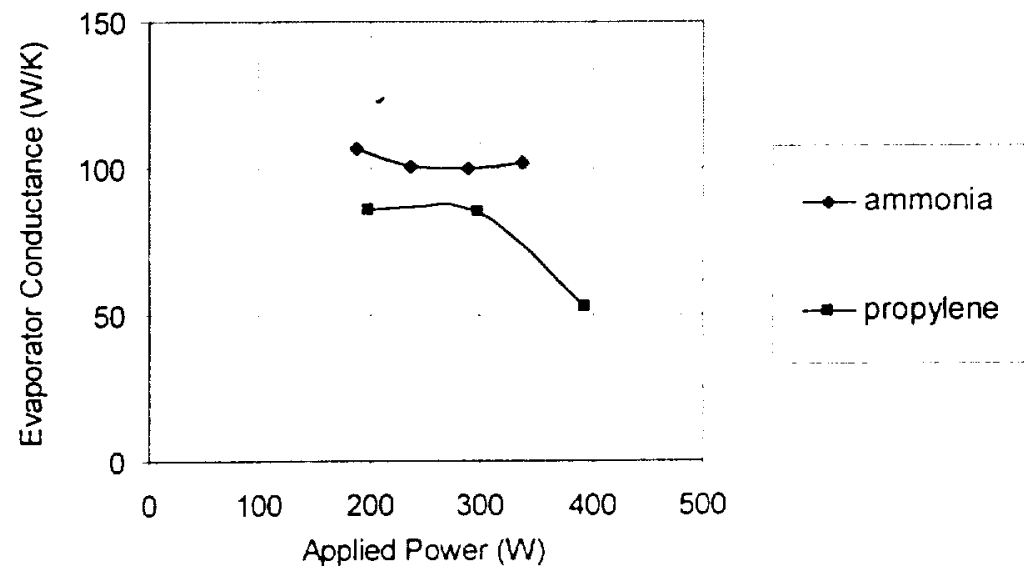

Figure 5. Evaporator thermal conductance as a function of applied power for ammonia and propylene LHP's. 


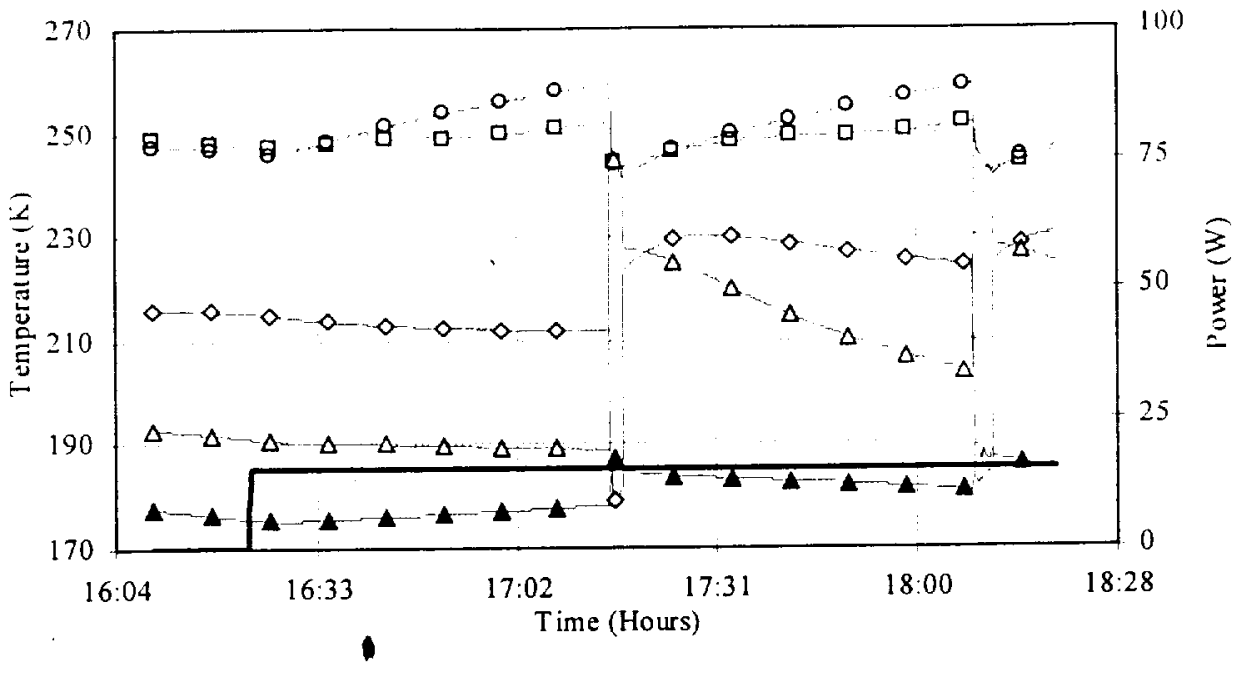

Figure 6. Temperature profiles for propylene LHP in vacuum during startup, Tsink=173 K. $[0$, average evaporator; $\square$, average compensation chamber; 0 , vapor line; $\Delta$, liquid line; $\boldsymbol{\Lambda}$, average condenser; , power].

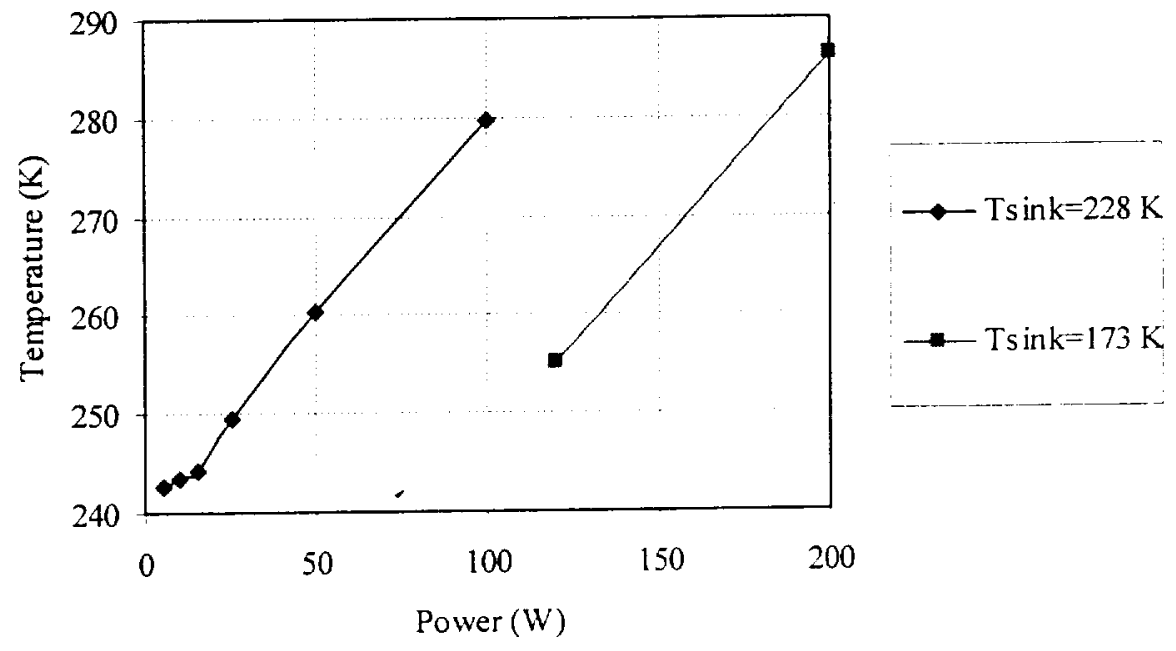

Figure 7. Operating temperature as a function of the applied power for propylene LHP in vacuum. 


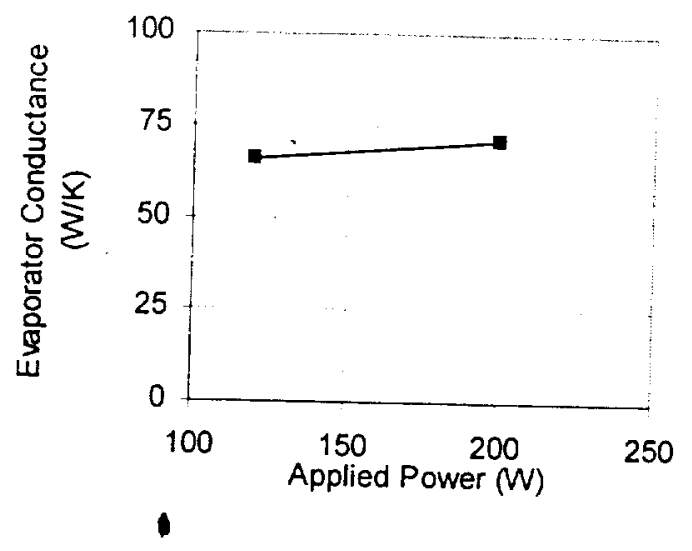
Figure 8 . Evaporator thermal conductance as a function of applied power for propylene LHP in
vacuum. Tsink $=173 \mathrm{~K}$. 